\title{
DC MOTOR SPEED CONTROL WITH FEEDBACK MONITOR BASED ON C\# APPLICATION
}

\author{
Prithviraj R. Shetti ${ }^{1}$, Ashok G. Mangave ${ }^{2}$ \\ ${ }^{1}$ lecturer, E\&TC Engg, Ashokrao Mane Polytechnic, Kolhapur, Maharashtra, India \\ ${ }^{2}$ lecturer, E\&TC Engg, Ashokrao Mane Polytechnic, Kolhapur, Maharashtra, India
}

\begin{abstract}
Precise, cheap control and monitoring the speed of DC motor is ever hot area of work. In the present paper we have attempted to implement speed control and feedback monitoring for a 12 Volt/1000 RPM rated motor. Speed control is done with help of PWM pins on Arduino/AVR board and H-bridge IC L293D. Feedback speed monitoring is based on IR pair based interrupt monitoring. Hence Sensing and calculation part of process is handled by Arduino/AVR board. All of this is implemented with help of PC based user interface developed in C\#. In a typical user interface speed control is achieved with help of trackBar and speed monitoring with help of Text window, was we get direct readout of current speed in RPM.
\end{abstract}

Keywords: Arduino/AVR board, PWM, DC motor, IR based speed monitoring using interrupt, C\# etc...

\section{INTRODUCTION}

DC motors are mainstay of electric traction drives on both electric and diesel-electric locomotives, street-cars/trams and diesel electric drilling rigs for many years. The introduction of DC motor and an electric grid system to run the machinery started in 1870's and cause second industrial revolution. Today DC motors are still found in toys and disk drives, or in large sizes to operate steel rolling mills and paper machines.[1] Speed Control of DC motor is a area we are always interested in. For the reason that the solution has to precise and more importantly cheap. Interested sectors include small/heavy industry and research laboratory. Here it is to be noted that speed control and speed regulation are different terms. For present project we demonstrate speed control. However since this application is PC based wherein we monitor current speed, it can be successfully modified for speed regulation tasks. With the help of present system user can control speed of DC motor with help of a friendly user interface. User can select direction of rotation viz. Clockwise/Anticlockwise at click of a button during any time of operation. He can select speed of rotation with help of trackBar. Stop motor with button click. And also monitor current speed in text window.

The development of such a system was assisted and made easy going by open source Arduino/AVR board which has ready to use PWM pins and also to mention the CMOS H-bridge IC L293D motor driver IC. It is possible to control direction and speed both with help of this IC.

\section{RELATED WORK}

Obviously the idea of DC motor speed control is not new. Particularly speaking, for the kind of motor we use in our project. We can find numerous authentic websites demonstrating speed control with help of Arduino[2] and L293D[3] which is a motor driver IC. In most cases potentiometer is used to demonstrate speed control using PWM capabilities of Arduino.

\section{PROPOSED SYSTEM}

Fig 1 shows the block level representation of system. IR pair is used monitor the speed of motor. Very cheaply available unmatched pair is used to have test results in bad conditions. The H-bridge motor driver IC L293D requires a +5 volt for operation and a separate $0-24$ volt external supply for motor. It is used to change speed and direction of motor. The PC based application has trackBar for speed control, Buttons to open/close serial port, change direction of rotation, stop motor and a text window for monitoring speed. Motor is 12 volt $/ 1000$ RPM rated motor.

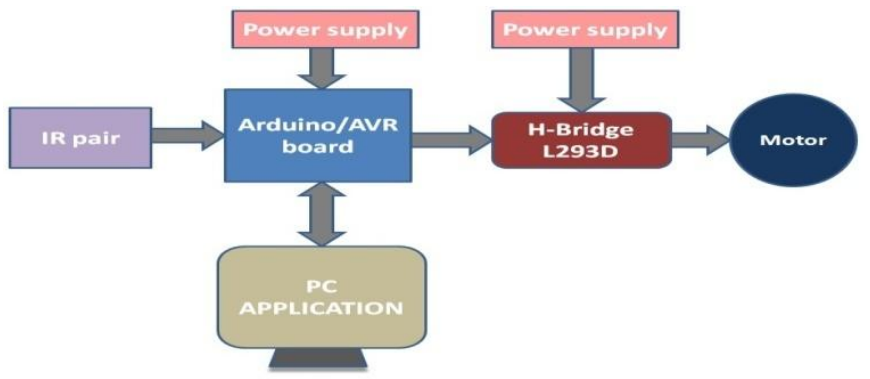

Fig -1: Proposed system 


\section{HARDWARE DESIGN}

\subsection{Arduino/AVR Board}

Either a standalone Arduino board or minimal Arduino configuration works fine. We used standard Arduino available as Freeduino board in India. Fig 2 shows sketch of circuit setup developed using fritzing[4].

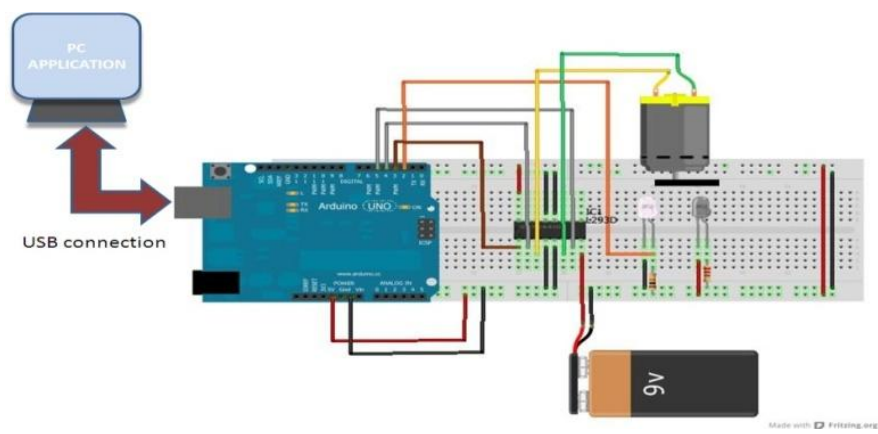

Fig -2: Circuit arrangement in fritzing

\subsection{Motor Driver Unit}

Motor driver unit has IC L293D. The pin connections can be found in datasheet[3]. logic for changing direction of motor and controlling motion in Table 1 . Table 1 indication the way pins must be configured for changing direction of rotation. Pins 2 and 7 of L293D are connected to Arduino pins4 and 5 respectively. These pins are used to control direction of rotation. Pin1 of L293D connected to PWM pin3 of Arduino. This pin is used to control speed of rotation. Values written in the range of $0-5$ volt on this pin change the speed of motor from 0-max rated.

\subsection{IR Pair}

IR pair is used for speed measurement. For this external interrupt int 0 of Arduino is used. On Arduino pin2 is available as int 0 . The photodetector cathode goes to +5 volt and junction of anode with $10 \mathrm{Kohm}$ resistance goes to int 0 . The other end of $10 \mathrm{Kohm}$ resistance is ground. Here the function of photodetector and $10 \mathrm{Kohm}$ resistance acts as source of interrupt. For present arrangement whenever something appears in the path of IR transmitter LED and IR detector, interrupt is applied to the Controller.

\subsection{Motor Unit}

Motor is 12 volt/1000RPM rated DC motor. Motor is connected to pins 3 and 6 of L293D.

\subsection{Power Supply}

External 0-24volt supply required for Motor. The supply is in actual connected between Pin8 of L293D and Ground. Arduino board itself receives power from USB cable used for serial communication.
Table -1: LOGIC TABLE FOR H-BRIDGE IC L293D

\begin{tabular}{|l|l|l|l|}
\hline EN & $1 \mathrm{~A}$ & $2 \mathrm{~A}$ & FUNCTION \\
\hline HIGH & LOW & HIGH & Turn CW \\
\hline HIGH & HIGH & LOW & Turn CCW \\
\hline HIGH & LOW & LOW & Stop \\
\hline HIGH & HIGH & HIGH & Stop \\
\hline LOW & Ignored & Ignored & Stop \\
\hline
\end{tabular}

\section{SOFTWARE DESIGN}

\subsection{Arduino Code}

Arduino code is written in $\mathrm{C}$ using the open source IDE. The two important commands used in program are digitalWrite(pin,HIGH) \& analogWrite(pin,value). Writing a high/low to any pin brings it to +5 volt $/ 0$ volt. Analog write function can be used in case of PWM pins. The flowchart corresponding to Arduino code is shown in fig 3.

\subsection{PC Application Code}

The PC based application is developed in C\# using windows forms. There are important functions to handle like opening/closing serial port, reading and characterising incoming serial data, reading button states and taking action accordingly. The flowchart corresponding to $\mathrm{C \#}$ code is shown in fig 4.

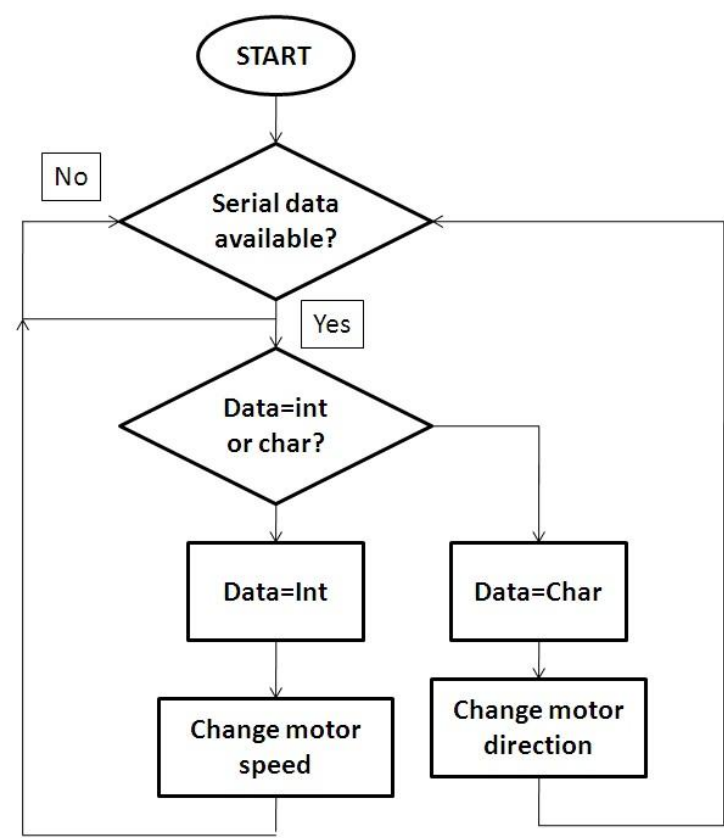

Fig -3: Flowchart for Arduino code 


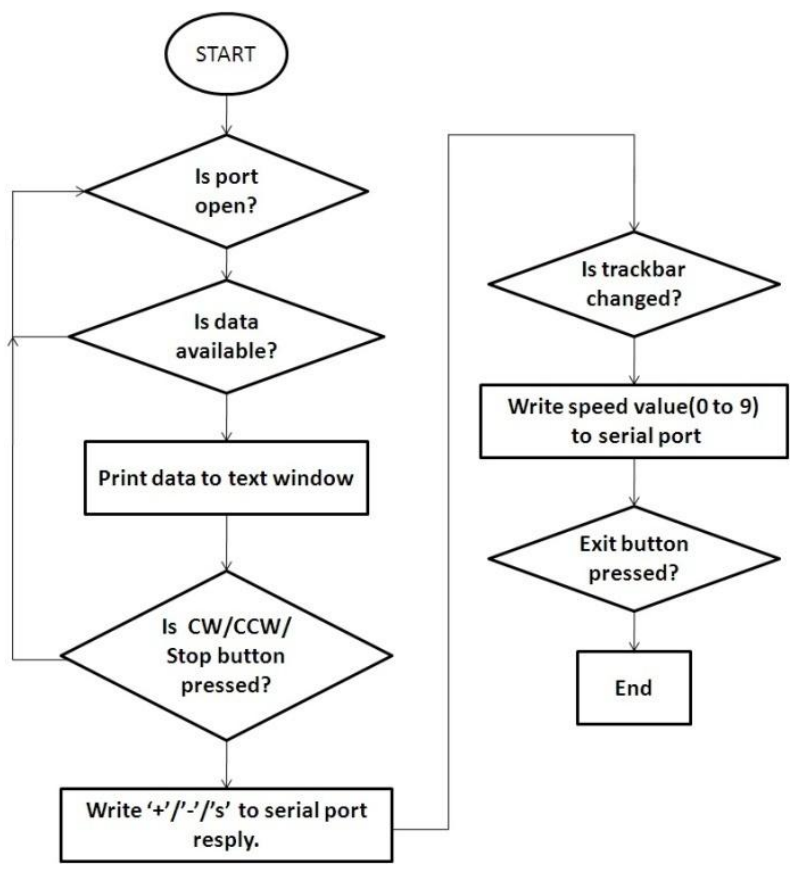

Fig -4: Flowchart for PC application code

\section{RESULT}

Fig5-6 show the photographs of actual setup in running mode and fig7. shows PC based User interface. Fig8-9 give more closer look. In the user interface we can see RPM readings displayed in text window.

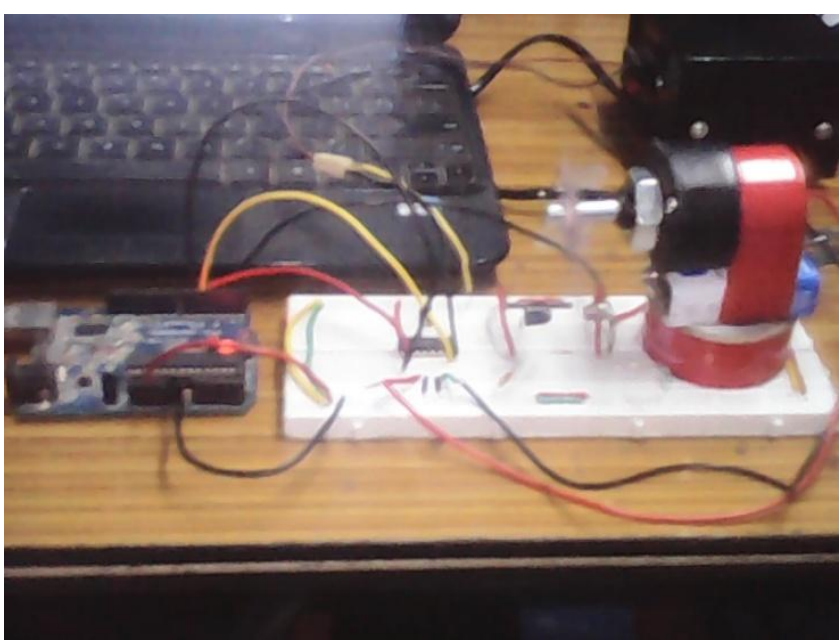

Fig -5: Running Demo

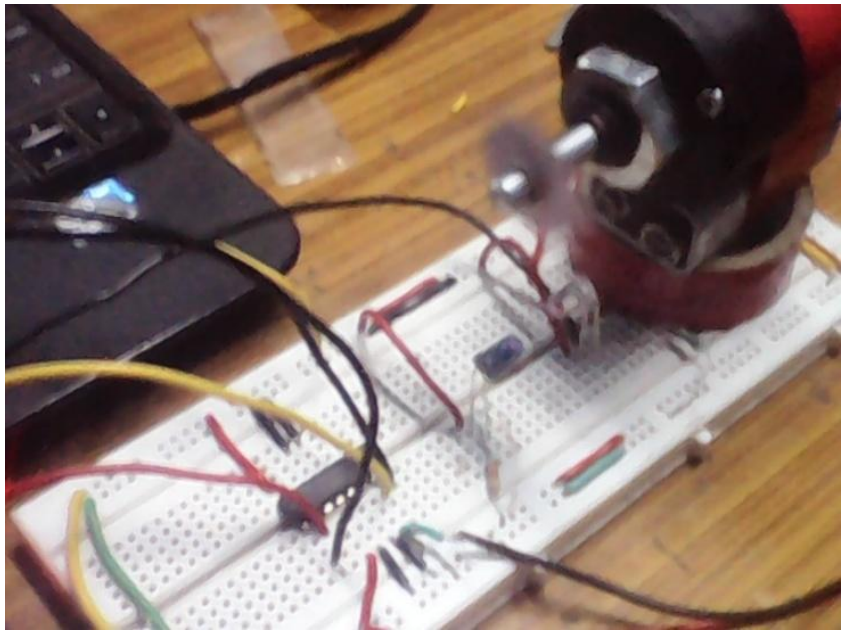

Fig -6: Running Demo (zoom)

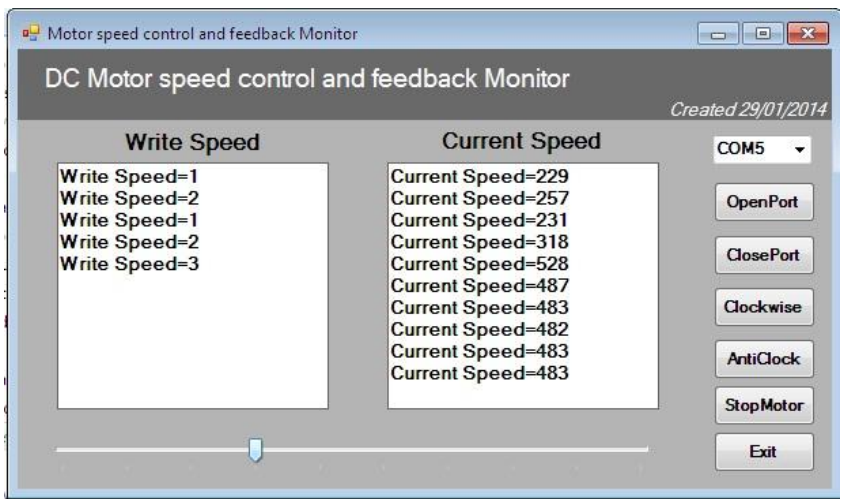

Fig -7: Running PC application

Motor speed control and feedback Monit

DC Motor speed control ar

\section{Write Speed}

Write Speed $=1$

Write Speed $=2$

Write Speed $=1$

Write Speed $=2$

Write Speed $=3$

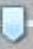

Fig -8: Running PC application (zoom) 


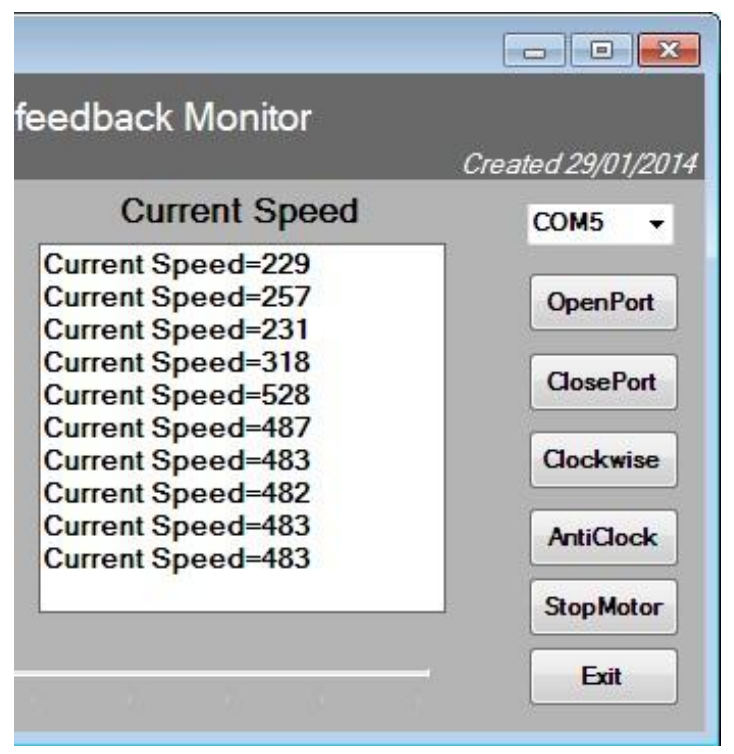

Fig -9: Running PC application (zoom)

\section{CONCLUSIONS}

Traditionally speed control is achieved based on potentiometer approach. We have tried to bring precision, neatness and user friendliness to the setup. The actual concept of hardware setup is recent but provision of $\mathrm{PC}$ based user interface has brought better usability and remote operation. But to mention, the readings obtained have a variation of $+/-10 \mathrm{RPM}$. We hope that we can improvise on this in future.

\section{REFERENCES}

[1]. http://www.en.m.wikipedia.org/wiki/DC_motor

[2]. http://www.playground.arduino.cc/main/DCMotorControl

[3].http://www.users.ece.utexas.edu/ valvano/Datasheets/L29

3d.pdf

[4]. http://www.fab.fritzing.org

\section{BIOGRAPHIES}

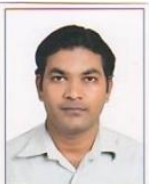

Prithviraj R. Shetti has received B.E in Electronics and Telecommunication from Shivaji University, Kolhapur in May 2006. His research interests include Embedded system design related to Electronics and electrical problems.ID:

prsece@gmail.com

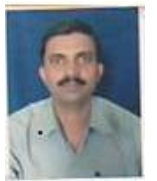

Ashok G. Mangave has received M.E in Electronics from Shivaji University, Kolhapur in Jan. 2014. His research interests include Control systems and Instrumentation. ID: mangave2404@gmail.com 